\title{
loT-based Smart Garbage Monitoring
}

\author{
Siti Sarah Md Ilyas ${ }^{1 *}$, Muhammad Amirul Rosyad Mohd Halim² ${ }^{2}$, Nadia Abdul Wahab ${ }^{3}$, Norfiza Ibrahim ${ }^{4}$ \\ 1,2,3,4 Faculty of Computer and Mathematical Sciences \\ Universiti Teknologi MARA, Perlis Branch, Arau Campus, 02600 Arau, Perlis, Malaysia
}

Corresponding author: *sarahilyas@uitm.edu.my

Received Date: 15 March 2021

Accepted Date: 30 March 2021

Published Date: 1 September 2021

\section{HIGHLIGHTS}

- IoT-based Computerised waste management system in a public university using IoT application with real time monitoring

- Ultrasonic sensors implementation to determine the height of garbage and percentage of humidity

- Live data monitoring with two display variations, from Blynk application and an LCD panel

- Conducted User Acceptance Testing to validate the acceptance of the system

\begin{abstract}
Smart Garbage Monitoring System using Arduino and Blynk is an IoT-based project that is integrated with cloud computing service. It was developed specifically to help janitors and residential college representative committee in a public university in Malaysia in monitoring the level of garbage in the dustbin through Blynk application, which makes it easy to empty the dustbin and optimize the garbage collection time. This project uses ultrasonic sensor to measure the level of garbage in the dustbin and the data can be viewed through mobile application, Blynk. It will also notify users through email once the garbage bin capacity is full. Other than notification function, Smart Garbage Monitoring System also consists of automatic open and close lid, track dustbin location and humidity level. The objectives of this project are to design the IoT system that detects the level of the garbage displayed in Blynk and an LCD attached to the dustbin and to validate the user acceptance test for the system. The development of Smart Garbage Monitoring System used the System Development Life Cycle (SDLC) by implementing the agile model as the methodology. A User Acceptance Testing was conducted with 20 respondents including students from the student representatives' body and janitors. This testing aimed to determine the acceptance of the system by conducting an evaluation. The results of the User Acceptance Test shows that most of the participants agreed and verified that the system works for them and a suitable solution for their problems. Therefore, based on the features and functionalities offered by the Smart Garbage Monitoring System, it could be concluded that this system is beneficial to all the users, especially the janitors and students of the residential college.
\end{abstract}

Keywords: smart garbage monitoring system, arduino, nodeMCU, ultrasonic sensor 


\section{INTRODUCTION}

Today in the age of rapid urbanization, hundreds of flats and apartments were built. This is due to high demands for housing, which have risen dramatically as a result of migration from villages to cities. The government has constructed more apartment complexes to accommodate the growing population in the urban area. The residents of the flats face several issues. One of them is solid waste disposal. The residents of all the apartments use a common dustbin, unlike private houses, which tend to fill up very fast. This overflowing of garbage may be a sanitary issue which could cause diseases like Indian cholera and break a bone (Anwar et al., 2018). At the educational sector, either schools or universities also have to keep the cleanliness of its surroundings. According to a statistic by Ministry of Higher Education (MOHE), public university in Malaysia receives in average of 28, 382 enrolments in 2019. Hence, there is many students that will occupy the residential colleges (Ministry of Higher Education, 2020).

Conventional way of waste management requires extra human efforts, time and cost (Ismail et al., 2019). To maintain university's clean environment, janitors are hired to take care of every part of the campus. A clean environment is essential in ensuring the staff and students from being exposed to any health issues. Other than that, prioritizing cleanliness can help to advocate the good image of a university campus. Usually, Campus Management will assign janitors to perform all the cleaning and waste management tasks in the residential college. The janitors must check every level of each residential college block to collect the waste daily. This requires them to check every single dustbin on every floor. The task will become more tedious if the campus has greater number of students. Generally, the janitors need to monitor and check thousands of dustbins every day.

For this project, the researchers have developed an IoT based for smart garbage monitoring system. The main function of this smart garbage is to monitor the garbage and humidity level in the dustbin through mobile application called Blynk. Users were able to view the infographic details of garbage level and humidity level via Blynk application. This helps the users to monitor the garbage level in the dustbin without needing to go to the dustbin which requires less human effort than the conventional ways. Users could also monitor the garbage level at anytime and anywhere though Blynk. This mechanism may help in improving the waste management in a university campus.

The system also has a special feature to track the location of the dustbin via the application. Last but not least, the user will receive an email notification if the garbage reaches 80 and 100 per cent of its capacity. This will alert the user to empty the dustbin before the garbage is overflowing. Furthermore, an LCD is attached to the dustbin as an interface for displaying the garbage and humidity level. Lastly, it also has automatic open and close lid functions that can ease people to throw garbage without any physical contact with the dustbin. This feature will be advantageous for hygienic practice to prevent diseases for example Covid-19 from spreading as a result from physical contact with shared objects or other individuals.

\section{PREVIOUS STUDIES}

This section is an overview several of related works on smart garbage monitoring system using various technologies, techniques and approaches conducted by the researchers. 


\section{IoT Based Smart Garbage and Waste Collection Bin}

This project is developed by Navghane, Killedar, and Rohokale (2016) aimed to feed real time information and present a ubiquitous value to waste management authority in an organization. The authority will notify the assigned garbage collector of the system indicate when the dustbin is full. With IoT implementation, the depth of the garbage inside the dustbin is shown on LCD panel and real time data is transmitted to ThingSpeak via ESP8266 WIFI module. Hence, the system will signify in operational cost, manpower and lower the road traffic.

The dustbin prototype is equipped with the microcontroller platform based on (ARM LPC2148) and have IR wireless systems connected to the central garbage status system. The combination of a weight sensor and an IR sensor is also used in this project to detect the amount of garbage in the dustbin and to provide the garbage level of dustbin status through mobile. This will change the status of the HTML site. The central part of this project depends on the Wi-Fi module, which is essential for its implementation. Figure 1 shows the transmitter block diagram, while Figure 2 shows the receiver block diagram.

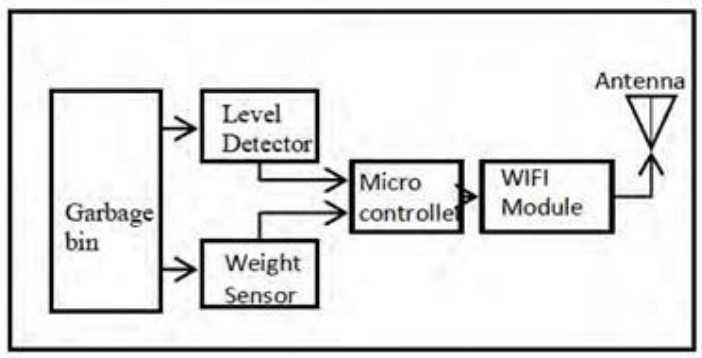

Figure 1: Transmitter

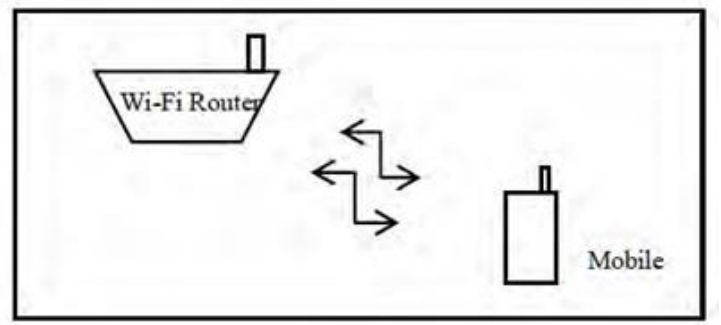

Figure 2: Receiver

According to Navghane, Killedar, and Rohokale (2016), the system mechanism has a high reliance to the availability of network. With low connectivity to the network, it will disrupt the system operation. Therefore, it is proposed to improve the system in the aspect of communication hardware development. Other than that, the author also proposes to impose garbage sorting by using image recognition.

\section{Smart Dustbin-An Efficient Garbage Monitoring System}

A Smart Dustbin is a project proposed by Monika, Rao, Prapulla, \& Shobha (2016). Based on IoT, the smart bin is built on a platform based on the Arduino Uno board interfacing with a GSM modem and an ultrasonic sensor. The sensor is located at the top of the bin. The sensor is placed at the edge of the tank. A level of threshold is set at $10 \mathrm{~cm}$. The sensor activates the GSM modem as the garbage exceeds the threshold 
level, which warns the relevant authority until the garbage in the bin is empty. In the end, it is concluded that the design of these smart bins addressed various issues such as affordability, maintenance, and durability. It also resulted in a hygienic and clean environment in the process of building a smart city.

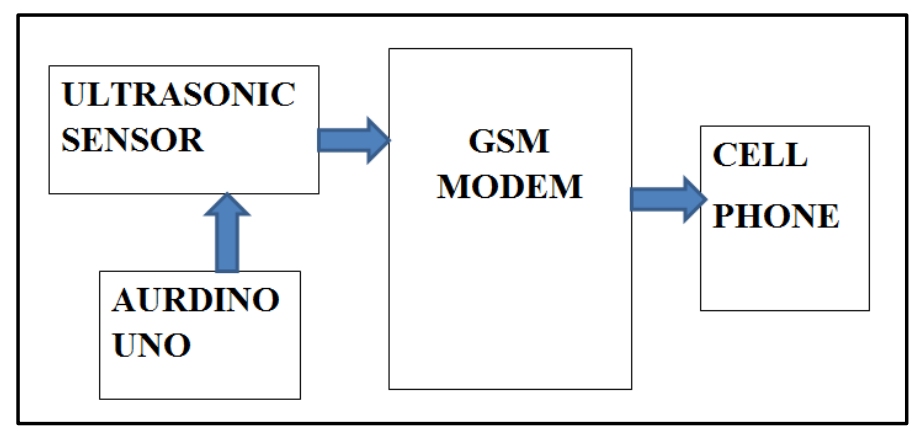

Figure 3: Block diagram of the system

From the previous works, it can be concluded that a smart garbage monitoring system should impose characteristic such as adept sensing mechanism, stable network capabilities, real time report and capacity to support waste management. This to ensure that the system is acceptable, suitable, efficient and effective to be used by the users.

\section{METHODOLOGY}

The System Development Life Cycle (SDLC) based on the agile model was used to develop the smart garbage monitoring system. It consists of five phases such as planning, design, development, testing and evaluation.

\section{Planning}

The planning phase is the initial phase to start a project. It is a lucrative step that acts as a blueprint for the researcher. In this phase, the main activity to conduct a feasibility study. All the related information, essential facts, and crucial data were extracted from previous researches, projects and articles gathered to support the research. The information is about IoT, software, tools and the framework used to implement this project.

\section{Design}

During the design phase, the researcher has designed the requirement needed for the system development. It implicates the plan for a solution which included the prototype visualization, system framework, and wiring diagram.

\section{Development}

In development phase, the process of converting the whole requirements and blueprints into a working system was done where all components of the hardware are assembled together. The ultrasonic sensor and humidity sensor were connected to the NodeMCU board as a microcontroller. The microcontroller was programmed in the Arduino IDE software. The code script was written to program entire hardware sensor 
functionalities with microcontroller. The ultrasonic sensor was placed on the lid while the humidity sensor was placed inside the dustbin. The distance between the ultrasonic and the garbage decreases as trash increases. The humidity sensor will sense the water vapour in the dustbin. As the percentage of humidity gets lower, the dustbin will be categorized as wet garbage. These data will be sent to NodeMCU with Arduino UNO as support for supply $5 \mathrm{~V}$ power. The NodeMCU then processes the data and sends the data to Blynk application.

\section{Testing}

Debugging and testing of the program for fixing wiring connection, bugs or error of the design were done in the testing phase. Then, the system was evaluated to determine the system performance and to ensure all requirements are accomplished. The test that was conducted towards the system is the User Acceptance Testing. This test was conducted with 20 users to determine whether the system works effectively and efficiently and a suitable solution to solve the users' problem regarding garbage management.

\section{Evaluation}

After testing phase, minor refinement was done to perform corrections of bugs and the user's feedback. This phase focused mainly on configuring, installing and usability issues.

\section{ARCHITECTURE OF THE PROPOSED SYSTEM}

The flow process for the Smart Garbage Monitoring Architecture process is shown in Figure 4. HC-SR04 ultrasonic sensor is placed on the lid of a garbage bin. This sensor will measure the gap between the lid and the highest point of the waste inside the garbage bin. The distance between the sensor and the garbage decreases as the trash increases.

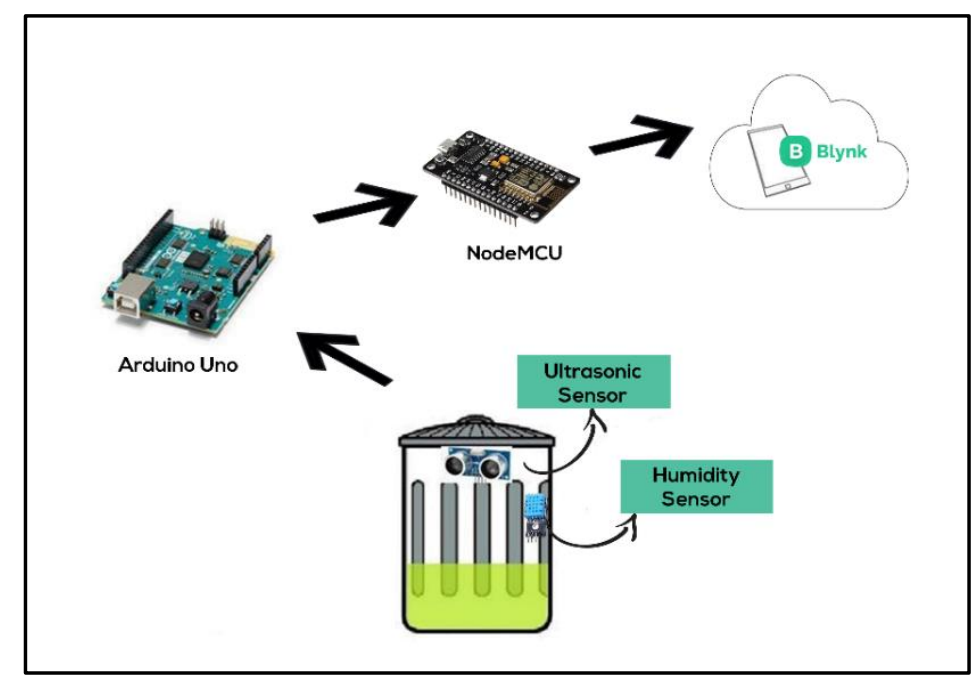

Figure 4: System Architecture 
To measure the relative humidity in the dustbin, DHT11 humidity sensor is positioned on the inside wall of the garbage bin. It helps user to know whether the waste in the dustbin is in state damp or dry. This will allow the user to prioritize the damp garbage bin to avoid undesirable smell from the waste decomposes.

The live data from both sensors are transferred to NodeMCU through Arduino Uno. Hence, the data is processed, with the assistance of the Wi-Fi module, the data is sent to cloud storage which is Blynk. With Blynk, users can monitor the garbage level via mobile. It guarantees an interactive monitoring system since it provides a graphical interface beside view. Users can benefit from two display options of the monitoring system, which are Blynk application and also information from the LCD.

\section{FINDINGS AND DISCUSSIONS}

To evaluate the user acceptance of the proposed system, an evaluation session was conducted. The evaluation utilizes the User Acceptance Test to verify whether the system is able to handle required tasks in real-world scenarios, according to its specifications.

\section{User Acceptance Testing}

The User Acceptance testing is conducted to make sure whether the system could handle required tasks in real-world scenarios, according to specifications (Hambling \& Goethem, 2013). This testing also aims to obtain users' feedback regarding the Smart Garbage Monitoring System based on four criterias which are ease of use, intention to use, design and purpose. Twenty (20) participants involved in this testing including fifteen students and five janitors from the residential college of a public university in Malaysia. During the testing session, all the respondents were introduced to the Smart Garbage Monitoring System, and all the features embedded in the system were explained. The participants were also given the chances to explore and use the system.

After using the system, the respondents were provided a set of evaluation form which containing 16 items. Evaluation has been done by utilizing the Google Cloud Form and the respondents were given the link to access the form online and answer the questionnaire for gather their feedback after the testing was carried out. Questionnaire was adapted from TAM assessment instrument (Weng et al., 2018). The analysis was evaluated based on the feedbacks of the questionnaire from the question provided to them. The respondents required to rate the answer with scale of 1 to 5 as shown in Table 1.

Table 1: Measurement scale

\begin{tabular}{cc}
\hline Value & Score \\
\hline 5 & Strongly agree \\
4 & Agree \\
3 & Neutral \\
2 & Disagree \\
1 & Strongly disagree \\
\hline
\end{tabular}

Then, overall mean was calculated and classified into three categories, which is negative, neutral and positive based on the range of mean value in between zeros to five as shown in Table 2 . This table will be used to identify the level of user's acceptance toward the proposed system. 
Table 2: Range of mean value

\begin{tabular}{cc}
\hline Range of Mean & Category \\
\hline $0.00-1.66$ & Negative \\
$1.67-3.33$ & Neutral \\
$3.34-5.00$ & Positive \\
\hline
\end{tabular}

Meanwhile, Figure 5 summarizes the results for the identified criteria and total mean for each category respectively. Based on the result obtained it can be said that, in general, the Smart Garbage Monitoring System using Arduino and Blynk are accepted by the users as the mean score for all categories were ranging from 4.32 to 4.37 . The total mean result for the perceived ease of use received 4.36 and intention to use received 4.37 respectively. Most of the respondents responded that they want to use the smart garbage monitoring system because the system is able provide an interface that clear and readable to monitor the garbage level through Blynk application. They also added that the system will save their time rather than manually checking each dustbin. This is based on total mean results obtained 4.34 for interface design and 4.32 for purpose. Meanwhile, the total mean for all four categories is 4.34. Therefore, based on the finding results and analysis, it can be concluded that Smart Garbage Monitoring System using Arduino and Blynk was well accepted by the users in all aspects, including its function and features.

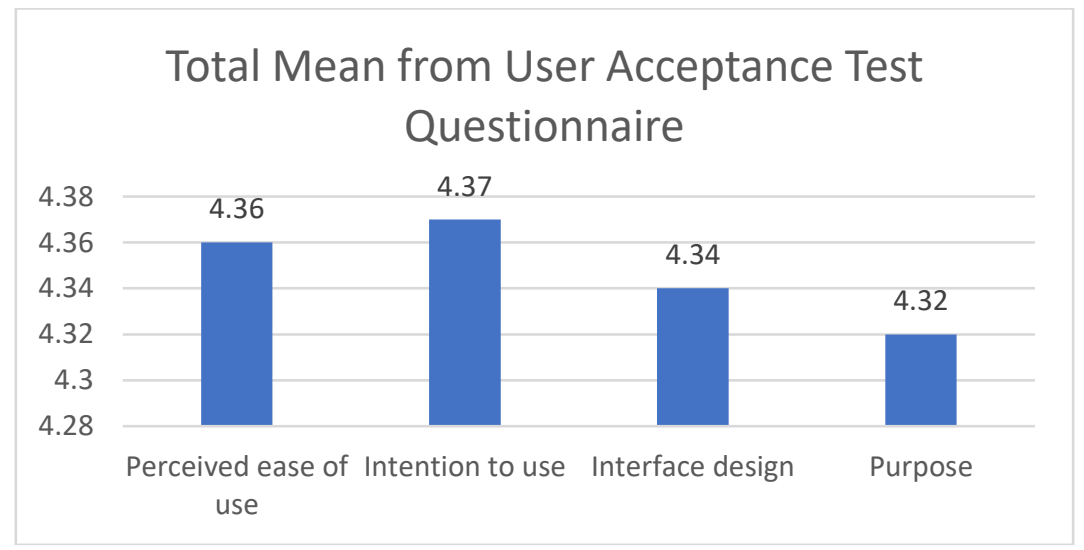

Figure 5: Total mean of each category

\section{CONCLUSION AND RECOMMENDATIONS}

Smart Garbage Monitoring System Using Arduino and Blynk was an IoT project developed to assist towards a better and more effective waste management in university campuses. This system helps the students and janitors by providing a new mechanism in emptying the garbage bin and thus reduce their energy and time. The recommendation for future works was described for future enhancement.

The system was evaluated using a User Acceptance Test to ensure that the system could handle all the required tasks according to specifications the system. The questionnaires were distributed to the participants during the testing. There were twenty (20) respondents participated in the testing. Most of the respondents were satisfied with the functionalities provided by the system and found that it was a great idea to develop a system that focused on the smart garbage monitoring system. This is indicated by the average means score for each category that were all above 4.0 
Upon the completion of the project, there are several recommendations and suggestions being made, by the participants involved in the evaluation of Smart Garbage Monitoring System. The first recommendation for the application was that the respondent suggested to view the humidity level of the waste in dry or wet as this system only display the humidity level in percentage. Another suggestion to categorize the waste in the dustbin as dry or wet rather than displaying the humidity in percentage to ease the users.

Besides that, the function of automatic open and close using SG90 server motor could also be improved. In current prototype, the dustbin lid is embedded with a IoT devices and sensors. The accumulated weigh restricts the lid to move upward. To overcome this limitation, the current server motor attached to the dustbin lid can be replaced with MG995 server motor which able to support to uplift heavier load which up to 11 kilograms. This can help users to easily put the waste inside without physical contact with the dustbin.

This paper has highlighted the use of IoT technology and the capabilities of Blynk application in enhancing the smart garbage monitoring system and achieve its objectives. In conclusion, Smart Garbage Monitoring System Using Arduino and Blynk was able to perform its functions such garbage level monitoring through the LCD and Blynk application, dustbin location detection and give notification when the dustbin is full. From the testing, the system also showed that the proposed system was positively accepted by the users as it meets the users' requirement and specification. Furthermore, this system has a very good potential in assisting universities to manage waste efficiently and effectively.

\section{REFERENCES}

Anwar, A., Sarkar, P., Dutta, R., \& Mollick, S. M. (2018). IOT BASED GARBAGE MONITORING USING ARDUINO. 27.

Hambling, B., \& Van Goethem, P. (2013). User acceptance testing: A step-by-step guide. BCS Learning \& Development

Ismail, M. H. bin, Razak, T. R., \& Abd Halim, I. H. (2019). An Implementation of Internet-connected Indoor Dust Bin Waste Level Monitoring System for Office Use. Journal of Computing Research and Innovation, 4(2), 42-48. https://doi.org/10.24191/jcrinn.v4i2.127

Ministry of Higher Education (MOHE). (2020). Statistik Pendidikan Tinggi 2019 : Kementerian Pengajian Tinggi. Retrieved from Ministry of Higher Education (MOHE): https://www.mohe.gov.my/en/download/awam/statistik/2019-1

Mohd Halim, A. R. (2020, May). Smart Garbage Monitoring System using Arduino \& Blynk \#Demo1YouTube. https://www.youtube.com/watch?v=Sj3BrU01Ksc

Monika, K. A., Rao, N., Prapulla, S. B., \& Shobha, G. (2016). Smart Dustbin-An Efficient Garbage Monitoring System.pdf. International Journal of Engineering Science and Computing (IJESC).

Navghane, S. S., Killedar, M. S., \& Rohokale, D. V. M. (2016). IoT Based Smart Garbage and Waste Collection Bin. 5(5), 3. 
Weng, F., Yang, R.-J., Ho, H.-J., \& Su, H.-M. (2018). A TAM-Based Study of the Attitude towards Use Intention of Multimedia among School Teachers. Applied System Innovation, 1(3), 36. https://doi.org/10.3390/asi1030036 